\title{
La influencia de la Narrativa Fantástica de H. G. Wells en el Rock'n'Roll
}

\author{
Jesús MARTÍNEZ NAVAJAS \\ Licenciado en Filología Inglesa (UPV) \\ jmartineznavajas@gmail.com
}

Recibido: febrero 2014

Aceptado: julio 2014

\section{RESUMEN}

Este artículo trata sobre la influencia de la Literatura en el Rock'n'Roll, mediante el estudio y análisis de dos canciones inspiradas en la Narrativa Fantástica de H. G. Wells, como son "The Invisible Man" de Queen y "Time Machine" de Black Sabbath. Su aplicación didáctica comienza con el acercamiento de los oyentes a los clásicos literarios que evocan estos temas que ya se han convertido en clásicos del género musical.

Palabras clave: Literatura comparada, Estudios Culturales Populares, H. G. Wells, Literary Covers, Rock'n'Roll.

\section{The Influence of H. G. Wells Fantastic Fiction in Rock'n'Roll}

\section{ABSTRACT}

This article deals about the influence of the Literature in Rock'n'Roll, by means of the study and analisys of two songs inspired by two H.G.Wells novels: "The Invisible Man" by Queen and "Time Machine" by Black Sabbath. Its didactic aplication starts with listeners approaching to the literary classics which evoke these songs which have become classics of the musical genre.

Keywords: Compared Literature, Popular Culture Studies, H. G. Wells, Literary Covers, Rock'n'Roll.

\section{L'influence du Roman Fantastique de H. G. Wells dans le Rock'n'Roll}

\section{RÉSUMÉ}

Cet article parle de l'influence de la littérature dans le Rock'n'Roll, au moyen de l'étude et de l'analyse de deux chansons inspirées des romans de H.G. Wells: "The Invisible Man" de Queen et "Time Machine" de Black Sabbath. Leur utilisation pédagogique commence par l'approche des auditeurs des classiques littéraires qui évoquent ces themes qui sont devenus des classiques du genre musical.

Mots clés: Littérature comparée, Études Cultureles Populaires, H.G. Wells, Literary Covers, Rock'n'Roll.

SUMARIO: 1. Introducción 2. H. G. Wells y la Ciencia Ficción 3. Estudio y análisis de dos Literary Covers sobre dos obras de H.G. Wells: The Invisible Man y The Time Machine 
4. Propuesta didáctica para su desarrollo en el aula Discografía

5. Conclusiones 6. Bibliografía y

\section{INTRODUCCIÓN}

Este artículo trata sobre la influencia de la Narrativa Fantástica de H. G. Wells en el Rock'n'Roll, con el objetivo de establecer una nueva vía en los estudios culturales populares ${ }^{1}$, enfocada a desarrollar una didáctica innovadora de los clásicos de la literatura. Igual que se ha hecho con el cine, este trabajo utiliza la metodología de la Literatura Comparada ${ }^{2}$. En esta ocasión se comparan textos literarios con musicales, señalando las conexiones existentes entre estas dos manifestaciones artísticas, tan relacionadas entre sí, y con ello se ofrece una nueva mirada tanto para el lector, como para el oyente.

La máxima expresión de esta conexión cultural son las Literary Covers o Versiones Literarias. Si una Cover es una canción basada en una canción ya existente, una Literary Cover es una canción cuya letra está basada en una obra literaria. Para realizar el estudio y análisis de estas canciones, he creído conveniente establecer, desde un punto de vista teórico, una categorización cuyo parámetro principal es su grado de fidelidad al texto literario original, ya que en ello se hace patente la influencia de la literatura en el Rock. De esta forma, la categoría o tipo A engloba las canciones con una gran fidelidad al original, casi total, ya que hay intertextualidad directa entre ambos discursos. La categoría B contiene canciones que son más o menos fieles al original, pero que difieren en algunos detalles. En la categoría $\mathrm{C}$ se puede encontrar todo tipo de adaptaciones, remakes, secuelas, precuelas, etc., y por esta razón es la más numerosa y frecuente. Por último, el tipo D está compuesto por adaptaciones totalmente libres del mito, que en ocasiones poco o nada tienen que ver con el original, y cuya utilización a menudo es mero reclamo.

1 A partir de los noventa, numerosos estudios culturales, como el de John Storey, consideran al Rock\&Roll como una subcultura específica y diferenciada dentro de la cultura popular generada por la música contemporánea.

${ }^{2}$ «La literatura comparada es el estudio de la literatura más allá de las fronteras de un país particular y el estudio de las relaciones entre la literatura y otras áreas de conocimiento o de opinión, como las artes (i.e. pintura, escultura, arquitectura, música), la filosofía la historia, las ciencias sociales (i.e. política, economía, sociología), las ciencias naturales, la religión, etc. En resumen, es la comparación de una literatura con otra u otras y la comparación de la literatura con otros ámbitos de la expresión humana» Definición de Henry H. H. Remak en su ensayo "La literatura comparada: definición y función": (Vega y Carbonell, 89) 
La elección de la Literatura Fantástica decimonónica en lengua inglesa como motivo de investigación ${ }^{3}$, además de por mi predilección hacia estas novelas, se debe principalmente a dos razones. En primer lugar es el movimiento literario que ha inspirado la mayor cantidad de versiones musicales, superando incluso a tendencias de la Literatura Fantástica contemporánea, como, por ejemplo, las novelas de terror de Stephen King, o la Literatura Fantástica Épica (o de espada y brujería) de J. R. R. Tolkien, entre otros. La segunda razón, y más importante, es que se puede evidenciar que tanto la Narrativa Fantástica decimonónica como el rock contemporáneo suponen una ruptura con el convencionalismo cultural de su época. En efecto, de igual manera que la obra de Wells se contrapone y desborda la temática habitual asumida por la cultura convencional de su momento, creando un nuevo universo que se desarrollará posteriormente, el Rock'n'Roll, más de un siglo después, supone también una alternativa contrapuesta al panorama musical más comercial (primero el pop y después el dance o la música electrónica más exitosa y edulcorada). Incluso se puede considerar que se produce un relevo del género gótico, el tercer relevo. Es sabido que los escritores del XIX, como R.L. Stevenson, Bram Stoker o Mary Shelley, heredan dicho género de la Literatura Gótica original que crearon Walpole o Radcliffe, entre otros, en el XVIII.

Con aportaciones como las del presente artículo, pretendo poner de manifiesto que el Rock'n'Roll es heredero del Género Gótico clásico, con sus producciones de calidad, desde finales del XX, y en el presente siglo XXI, y que prolongan su influencia estética, por ejemplo, en el look estereotipado de ropa negra y maquillaje blanco, característico de las bandas de Gothic Rock o Rock Gótico, así como, sobre todo, en la temática y motivos que se reflejan en las contemporáneas Literary Covers de muchos subgéneros de Rock'n'Roll, sobre todo los derivados del Heavy Metal, máxima expresión del legado gótico. Así mismo, el comprobar que la temática de la narrativa de $\mathrm{H}$. G. Wells se retoma en composiciones musicales de artistas rockeros muy representativos de ese género musical y su evolución permite evidenciar la vigencia de la Narrativa Fantástica Victoriana, así como recalca su actualidad a día de hoy con un género como la Ciencia Ficción, que, a partir de Wells, ha estado presente en muchas otras manifestaciones culturales y forma parte del imaginario popular occidental.

${ }^{3}$ En este artículo expongo algunas de las cuestiones que trabajo con más profundidad y extensión para la tesis doctoral que estoy realizando en la UNED, La Influencia de la Literatura Fantástica decimonónica en lengua inglesa en el Rock'n'Roll: Estudio y análisis de algunas Literary Covers sobre la base de obras de siete autores ingleses del siglo XIX. 


\section{H. G. WELLS Y LA CIENCIA FICCIÓN}

Herbert George Wells es el precursor de la Ciencia Ficción moderna. Nace en 1866 en el condado de Kent (Inglaterra), de familia humilde, con formación científica, fue escritor y periodista, defensor de la justicia social y la paz mundial,hasta su muerte en 1946. Sus relatos de carácter social, político y moral que cuestionan la Ciencia y la Tecnología, sus resultados y la utilización responsable de los mismos. Las inquietudes estéticas y éticas tratadas por Wells han llegado a nosotros y se reflejan en muchas manifestaciones artísticas, tanto en los ecos musicales de las Literary Covers, como en las películas de ciencia ficción, sobre todo las de serie B. No olvidemos, por ejemplo, que en 1938, la costa este americana tembló al oír la adaptación radiofónica de The War of the Worlds, narrada en primera persona por Orson Welles. A España llegó la fama de Wells como escritor de la mano de Ortega y Gasset desde Londres. Ya se sabía de su socialismo fabiano junto con Bernard Shaw; también Azaña habla en sus memorias de la "Semana de Wells", celebrada en Madrid en 1920. Sus obras de ficción habían traspasado fronteras y eran auténticos best-sellers en su tiempo. Wells evoluciona desde la literatura de ficción a la de la anticipación sociológica y critica al socialismo fabiano que había compartido en su día. Su calado político en sus entrevistas con F. D. Roosevelt, Lenin y Stalin conciencia al mundo para reconstruir la sociedad, y su interés constante por el cambio y el progreso ha conformado su obra llena de esfuerzos por anticipar el futuro; acuñó la frase emblemática que ahora debería de ser de todos: "Si no acabamos con la guerra, la guerra acabará con nosotros."

Efectivamente, H. G. Wells está considerado precursor y pionero de la Ciencia Ficción junto con Julio Verne, cuyo énfasis en la aventura y lo maravilloso adopta un punto de vista juvenil (inocente y optimista) que los diferencia claramente. H.G. Wells destaca por su visión crítica del desarrollo tecnológico y el mal uso, normalmente abuso, de la Ciencia por parte de la humanidad, adoptando una perspectiva que la hace mucho más interesante y que certeramente se ha denominado "apocalíptica". De hecho, la mayoría de las obras, sobre todo de cine, literatura, comic, música, etc, que se engloban dentro del género se pueden considerar herederas de las ideas creadas por este genial escritor. De entre toda su obra destacan: The Time Machine (1895), The Island of Dr. Moreau (1896), The Invisible Man (1897) y The War of the Worlds (1898), que conforman el corpus fundamental de su ciencia ficción. En estas obras se encuentran los indicios que sustentan los convencionalismos del género: desde el viaje en el tiempo a la experimentación con seres humanos o con animales (anticipando la manipulación genética, la mutación y la clonación) hasta llegar a la existencia de alienígenas hostiles en platillos volantes y con rayos de la muerte.

De las diferentes canciones que he analizado, he escogido para este artículo estos dos temas musicales interpretados por dos grandes artistas del mundo del Rock'n'Roll que, igual que el escritor, han inspirado diferentes subgéneros 
musicales, y dan fe de la vigencia, casi cien años después, de estas dos grandes invenciones: la invisibilidad y el viaje en el tiempo. Efectivamente, estas versiones literarias son dos ejemplos de la huella, incluso sonora, que Wells ha dejado implícita para los siglos venideros, y que como no podía ser de otra manera, tenía que tener su reflejo en una tendencia artística tan creativa y revolucionaria como ha sido, y es, el Rock\&Roll.

\section{ESTUDIO DE DOS LITERARY COVERS SOBRE DOS OBRAS DE H.G. WELLS: THE INVISIBLE MAN Y THE TIME MACHINE}

\subsection{Análisis de la literary cover sobre the invisible man}

A) QUEEN

The enormously popular British band Queen epitomized pomp rock, with elaborate stage setups, smoke bombs, flashpots,lead singer Freddie Mercury's half-martial, half-coy preening onstage, and highly produced much-overdubbed music on record. [...] Queen's sound combined showy glam rock, heavy metal, and intricate vocal harmonies produced by multitracking Mercury's voice. May's guitar was also thickly overdubbed. [...] Heavy-metal fans loved Queen (despite Freddie Mercury's onstage pseudo-dramatics, wich had more to do with his admitted influence Liza Minnelli than with Robert Plant), ... (Rolling Stone, 794)

Como es sabido, Queen es una banda británica de Rock formada en 1970 por Freddie Mercury (voz), Brian May (guitarra), John Deacon (batería) y Roger Taylor (bajo). El grupo gozó de una gran éxito en Gran Bretaña a mediados de los 70, y tuvieron una significativa repercusión en EEUU a mediados de los 80, con un numeroso repertorio de éxitos a nivel mundial. Destacaron por su diversidad musical, arreglos en múltiples capas y armonías vocales, y se les considera una banda de gran influencia en el desarrollo del Hard Rock y el Heavy Metal, incorporando elementos de Glam Rock, Rock progresivo, Folk, Blues y Pop. Fue la primera agrupación musical en hacer de sus conciertos vistosos espectáculos con todo tipo de efectos escénicos que combinaban humo, flashes, luces móviles y ,sobre todo, el gran carisma de Freddie Mercury. Tienen en su haber un total de catorce álbumes de estudio, cinco álbumes en vivo y numerosas recopilaciones; con más de 300 millones de discos vendidos, es uno de los conjuntos más exitosos de todos los tiempos. A pesar de las bajas de dos de sus miembros (Deacon se retiró de la industria musical y Freddie Mercury falleció en 1991 a causa del sida) la sociedad artística nunca se disolvió, May y Taylor han continuado junto a artistas invitados como en Queen + Paul Rodgers de 2004 a 2009.

$\mathrm{Su}$ discografía es un ejemplo de la gran variedad de registros y subestilos que caracteriza la evolución del Rock'n'Roll. Desde sus primeros álbumes Queen (1973) y Queen II (1974), en el que aparecen por primera vez las voces operísticas, 
se hacen un hueco en la industria musical y en la escena del Hard Rock, sobre todo con Sheer Heart Attack (1974), considerado por muchos como el primer álbum de Power Metal. Pero el disco que llamó la atención internacionalmente y colocó a la banda en un primer plano del panorama musical fue $A$ Night at the Opera (1975), una de las obras clave del Rock sinfónico. Grabado en el por entonces novedoso sonido estereofónico, contiene la soberbia "Bohemian Rhapsody", considerada por muchos críticos como su mejor canción. Dicho disco es un clásico del Rock'n'Roll moderno, cuya presentación audiovisual para la BBC, que la banda produjo ante la imposibilidad de actuar en directo, como era lo habitual, dio lugar al nacimiento del videoclip ${ }^{4}$, uno de los instrumentos fundamentales para la difusión del Rock y de la música en general. A continuación en A Day at the Races (1976) se editan los legendarios temas "We Will Rock You" y "We Are The Champions", que se convertirán en famosísimos himnos deportivos, dando lugar al Arena Rock o Stadium Rock.

Más tarde se produce un nuevo ciclo en el que la banda da rienda suelta a la experimentación implementando nuevos estilos musicales que, aunque ablandaron su sonido, exploraron nuevos territorios para el Rock'n'Roll, anticipándose al Dance Rock, estilo combinado con la música electrónica, que eclosionó en los 90 y tan en boga está hoy día en pleno siglo XXI. De esta época son News of the World (1977), Jazz (1978), The Game (1980), en el que por primera vez se incorporan sintetizadores, a pesar de que en sus anteriores discos nunca los habían usado y así lo señalaban, y que contiene su gran hit "Another one bites the dust now", en una onda claramente más disco o pop; Flash Gordon soundtrack (1980) y Hot Space (1982), que incluye "Under Pressure" con David Bowie, la primera grabación con un artista invitado. La esperada vuelta al Hard Rock fue en The Works (1984), con cortes tan auténticos como "I Want to Break Free", "Radio Ga-Ga" y "Hammer to Fall", icónico tema del Hard Rock sobre la guerra fría. Sus últimos discos consolidaron su legado musical, sobre todo el exitoso penúltimo A Kind of Magic (1986), con clásicos como la homónima "A Kind of Magic", la legendaria "Friends Will Be Friends", "One Vision" (B.S.O. de Top Gun) y algunos temas de la banda sonora de la película The Highlander (Los Inmortales) como "Who Wants To Live Forever" y "Princes Of The Universe".

La Literary Cover que nos ocupa aparece en The Miracle (1989), último álbum de la formación que, como muchos de sus anteriores discos, fue $\mathrm{n}^{\circ} 1 \mathrm{en}$ el Reino Unido, a pesar de haber perdido los primeros puestos de las listas

\footnotetext{
${ }^{4}$ En los videoclips, la música es realzada con el poder evocador de la imagen, ya que es una especie de corto filmado para la banda sonora, es decir, la imagen se supedita a la verdadera protagonista que es la música. En el ámbito didáctico ofrece muchas posibilidades, como se pone de manifiesto en el comentario e interpretación y la unidad didáctica propuesta.
} 
americanas, y, sobre todo, fue una de sus obras más inspiradas, que evidenció la profunda unión de la entidad artística, como prueba el hecho de que todas las canciones están acreditadas a Queen y no a miembros de la banda; además, la portada consiste en la unión de las caras de los cuatro integrantes mediante el uso de Quantel Paintbox. En las letras se incluyen reflexiones sobre los logros pasados del conjunto y sobre el estado del mundo en los años 80 , como el single principal "I Want it all" o el tema escogido para su análisis en este artículo, que fue el tercer sencillo. Otros temas, como "Breakthru", "The Miracle" y "Scandal" también fueron reforzados por videoclips de gran calidad, que apoyaron su difusión.

B) LETRA ORIGINAL Y TRADUCCIÓN ${ }^{5}$

"The Invisible Man"

I'm the invisible man,

I'm the invisible man,

Incredible how you can,

See right through me,

When you hear a sound,

That you just can't place

Feel somethin' move

That you just can't trace.

When something sits

On the end of your bed

Don't turn around

When you hear me tread.

I'm the invisible man,

I'm the invisible man

Incredible how you can

See right through me

I'm the invisible man

I'm the invisible man

It's criminal how I can

See right through you.

Now I'm in your room

And I'm in your bed

And I'm in your life
"EI Hombre Invisible"

Soy el hombre invisible

Soy el hombre invisible

Increíble cómo puedes

Ver a través de mí.

Cuando oigas un sonido

que no puedes situar

sientas algo moverse

que no puedas localizar.

Cuando algo se sienta

al borde de tu cama

No te vuelvas

Cuando oigas mis pasos

Soy el hombre invisible, Soy el hombre invisible Increíble cómo puedes Ver a través de mí.

Soy el hombre invisible

Soy el hombre invisible

Es un crimen cómo yo puedo

Ver a través de ti.

Ahora estoy en tu habitación

y dentro de tu cama

y dentro de tu vida

\footnotetext{
${ }^{5}$ Todas las traducciones de las letras de las canciones han sido realizadas por el autor del artículo.
} 
And I'm in your head

Like the CIA

Or the FBI

You'll never get close

Never take me alive

I'm the invisible man,

I'm the invisible man

Incredible how you can

See right through me

I'm the invisible man

I'm the invisible man

It's criminal how I can

See right through you.

Hah, hah, hah, hello,

Hah, hah, hah, hello,

Hah, hah, hah, hello-hello-hello-hello,

Never had a real good friend not a boy or a girl

No-one knows what I've been through let my flag unfurl

So make my mark from the edge of the world,

From the edge of the world,

From the edge of the world,

Now I'm on your track

And I'm in your mind,

And I'm on your back

But don't look behind

I'm your meanest thought

I'm your darkest fear

But I'll never get caught

You can't shake me, shake me dear,

I'm the invisible man,

I'm the invisible man

Incredible how you can

See right through me

I'm the invisible man

I'm the invisible man y dentro de tu cabeza.

Como la CIA

o el FBI.

Nunca se me acercarán

Nunca me cogerán vivo.

Soy el hombre invisible

Soy el hombre invisible

Increíble cómo puedes

Ver a través de mí.

Soy el hombre invisible

Soy el hombre invisible

Es un crimen el que yo pueda

Ver a través de ti.

Hah, hah, hah, hola,

Hah, hah, hah, hola,

Hah, hah, hah, hola, hola, hola

Nunca tuve un buen amigo ni chico, ni chica

Nadie sabe en qué estoy metido deja mi bandera desplegar

Así dejo mi huella desde el final del mundo

Desde el borde del mundo

Desde el borde del mundo.

Ahora estoy tras tu pista

$Y$ estoy en tu mente

$\mathrm{Y}$ estoy a tu espalda

pero no mires detrás

Soy tu peor pensamiento

Soy tu miedo más oscuro

Pero nunca me cogerán

No puedes menearme

Soy el hombre invisible

Soy el hombre invisible

Increíble cómo puedes

Ver a través de mí.

Soy el hombre invisible

Soy el hombre invisible 
It's criminal how I can

See right through you.

Look at me, look at me
Es criminal cómo yo puedo

Ver a través de ti.

Mírame, mírame

\section{C) COMENTARIO E INTERPRETACIÓN}

Esta canción de Queen es una Literary Cover de tipo C, ya que es una adaptación contemporánea del personaje de Wells, que, diferencias aparte, conserva lo fundamental, la maldad, tal y como se sugiere en el videoclip con el personaje, representado en los cuatro integrantes de la banda, como el villano de un videojuego que escapa de la pantalla a la realidad. Sin embargo, como es habitual en este tipo de trabajos, por su finalidad y corto formato, la cuestión argumental pierde en favor de otros detalles puramente estéticos, que, por otro, lado hacen del video una obra de culto con esa estética ochentera de gafas de sol, trajes negros, rayos analógicos, etc. Por este motivo me parece conveniente descartar la interpretación del videoclip en favor de las dos que se proponen en este comentario.

A pesar del tono un tanto ingenuo de la letra, que, sin embrago, permite una segunda lectura connotada sexualmente, la primera y principal interpretación sugiere que las intenciones de este hombre invisible moderno se asemejan bastante a las del original decimonónico: instaurar un reino de terror mundial tal y como se expone al final de la novela:

«The point is, they know there is an invisible Man - as well as we know there

is an invisible Man. And that Invisible Man, Kemp, must now establish a

Reign of Terror. Yes; no doubt it's startling. But I mean it. A Reign of Terror...» (Wells, 119).

Después de casi cien años, el modo más apropiado para conseguirlo es el espionaje de altos vuelos a lo James Bond, y si no tenemos en cuenta el videoclip, ésta parece ser la lectura más apropiada para el contexto socio-político de finales de los 80, el final de la guerra fría. En este sentido, y a pesar de que han transcurrido 25 años, se puede hablar de un contexto actual, puesto que hoy en día el espionaje cibernético, tipo Wikileaks, con el caso de Snowden por ejemplo, está a la orden del día.

El elemento contemporizador de la letra de la canción, que la sitúa a finales del siglo XX, es la alusión a la CIA y al FBI, que, además, refuerza la idea de las globalmente malignas intenciones que este hombre invisible tiene. Hay diferentes partes de la letra que asocian, e incluso califican, las acciones del personaje como las de un archicriminal, su ambición no tiene límites, su verdadera declaración de intenciones es: «No-one knows what I've been through - let my flag unfurl / So make my mark from the edge of the world.»

Se puede inferir que el nuevo personaje tiene unas pretensiones similares a las del protagonista de la novela original, prueba de ello es que está buscado por las 
dos principales organizaciones de seguridad de EEUU, prácticamente se puede decir que de todo el mundo, y encima se jacta de ello "You'll never get close / Never take me alive». Además, se incluyen un par de claras alusiones a la maldad de sus actos, como en «I'm your meanest thought / I'm your darkest fear», donde él mismo se define como malvado, acto frecuente de los villanos. Por último, y quizás más importante, en una parte del coro que se repite tres veces, se alternan los adjetivos "increíble" y "criminal", para referirse a las dos principales características de este individuo: "Incredible how you can / see right through me», lo que es increíble es su invisibilidad, que se pueda ver a través de él, y lo que es criminal son sus acciones «It's criminal how I can / See right through you», se puede interpretar que su invisibilidad le permite ver "a través de los demás", en el sentido de que puede espiar sus vidas, puesto que la única persona que realmente es invisible es él. Otro verso que subraya este espionaje "extremo" es "And I'm in your mind», que más que a poderes telepáticos, se refiere a la facilidad que la invisibilidad le da para predecir los movimientos e incluso los pensamientos ajenos.

Por otro lado, podemos proponer una segunda lectura mucho más ingenua, como he dicho anteriormente, incluso algo inocente, en la que parece que la única preocupación del personaje es colarse en los dormitorios. Para sustentar esta interpretación del hombre invisible como el voyeur definitivo, prácticamente indetectable, hay dos partes en la letra de la canción, que parecen distraer la atención del oyente en esta dirección. La primera anticipa y da a entender esta lectura tan connotada, si no sexualmente, con un tono sensual un tanto pícaro, «When something sits / On the end of your bed». La segunda son cuatro versos en los que el vocalista usa un tono que en gran medida amplía y satiriza el contenido: «Now I'm in your room / And I'm in your bed / And I'm in your life / And I'm in your head.» Si bien estas intenciones ablandan a este hombre invisible moderno, también abren una nueva hipótesis sobre cuál es su objetivo y, aunque parezca mucho menos interesante, seguramente esta lectura "picante" tuvo y tiene un gran tirón entre el público seguidor de la banda, tanto el femenino como el masculino, debido a la reconocida y abierta homosexualidad del cantante. De hecho, en el videoclip la escena en la que la banda abandona el videojuego y aparece en la realidad se sitúa precisamente "saliendo de un armario".

En el aspecto musical a pesar del sonido electrónico, con esos sintetizadores y arreglos digitales, el tema tiene una gran "pegada" que lo aleja del pop y la música disco. El protagonismo lo cobran los elementos de sonido Rock, como el contundente riff de bajo que Roger Taylor compuso tras leer el libro y que fue la base sobre la que el grupo empezó a trabajar, o el extraordinario y técnico solo de Brian May, clara muestra del uso de diferentes capas tan habitual en el guitarrista, el cual es presentado por el vocalista, algo muy frecuente en directo, pero inusual en un tema en estudio. De hecho una peculiaridad de la composición es que aparecen los nombres de los músicos (aunque los otros tres suenan de fondo) dando 
fe de la solidez de la sociedad artística y de la fuerte unión de los integrantes de la misma, otro destacable detalle de este álbum que desgraciadamente fue el último. Este sonido tan tecnológico supone la ambientación perfecta para este nuevo hombre invisible, superespía de finales de los 80; la base de guitarra acompañada de esos teclados es un destacado exponente del sonido Heavy Rock de Queen, con la majestuosa voz de Mercury a la cabeza.

\subsection{Análisis de la literary cover de time machine}

\section{A) BLACK SABBATH}

Black Sabbath es una de las primeras y más influyentes bandas de Heavy Metal de todos los tiempos que ayudó a desarrollar el género con discos considerados verdaderas obras maestras y cuya popularidad, más de 15 millones de copias sólo en Estados Unidos, acercó el fenómeno a un público mayoritario. Su legado musical es tan amplio que ha inspirado incluso subgéneros, como el Doom Metal o el Stoner Rock; a lo largo de las diferentes etapas, ha tenido un desfile de músicos, grandes personalidades del mundo del Rock en general y precursores del Heavy Metal en particular, por su formación. Todo ello les ha hecho ganarse un merecido status de auténticos reyes del género.

Mixing equal parts bone-crushing volume, catatonic tempos, and ominous pronouncements of gloom and doom delivered in Ozzy Osbourne's keening voice, Black Sabbath was the heavy-metal king of the '70s. [ ... ] In spite of their name, the crosses erected onstage, and songs dealing with apocalypse, death, and destruction, the band members insisted their interest, in the black arts was nothingmore than innocuous curiosity. (Rolling Stone, 81)

En Birmingham, en 1968, los amigos de la infancia Tony Iommi (guitarra), Ozzy Osbourne (voz), Geezer Butler (bajo) y Bill Ward (batería) formaron originalmente una banda de Blues Rock, Polka Tulk, hasta que decidieron crear el equivalente a las películas de miedo en el Rock'n'Roll, en respuesta al "flower power" reinante en la década de los 60. Con este objetivo, incorporaron letras sobre terror y ocultismo, crearon un sonido con guitarras afinadas de modo más grave e hicieron uso, sin ser conscientes de ello, del tritono (también conocido como "el intervalo del diablo") así como cambiaron su nombre por Black Sabbath, inspirado en el título de una película de serie B de Boris Karloff y el trabajo del escritor ocultista Dennis Wheatly. Este sonido siniestro con letras oscuras les encumbró, a pesar de ser incomprendidos por la crítica de su época. Esta formación clásica con los miembros originales, hasta el despido de Ozzy en 1979, está considerada como la época dorada de la banda y uno de los períodos más fructíferos en lo que a discos, como piezas clave de la evolución del género, se refiere. De esta época son Black Sabbath (1970), Paranoid (1971), con las emblemáticas canciones "War pigs", "Iron Man" y "Paranoid", Master of Reality (1972), Black Sabbath vol.4 (1972), Sabbath Bloody Sabbath (1973), Sabotage (1975), Technical Ecstasy (1976) y Never Say Die! (1978). El exceso de trabajo y 
las drogas acabaron con la estabilidad de esta primera formación; a partir de la marcha de Ozzy Osbourne (para comenzar su carrera en solitario) y a pesar de sus retornos, el ir y venir de músicos será continuo, no llegando a completar un período tan largo y provechoso como éste primero.

El sustituto de Osbourne fue Ronnie James Dio, antiguo vocalista de Rainbow, quien produjo un marcado cambio en varios aspectos, desde el contenido lírico de los temas hasta su estructura musical. Su primera etapa dió lugar a la publicación de Heaven and Hell (1980) y Mob Rules (1981), que gozaron de una considerable aceptación por la crítica y los aficionados, convirtiéndose varios de sus temas en clásicos del grupo. A pesar de este legado musical, el choque entre las fuertes personalidades de Dio y Iommi, quien ha liderado la banda desde que la formó tomando decisiones tan difíciles y directas (como despedir a su amigo de la infancia de la batería) ha dado lugar a todo tipo de leyendas y rumores. Se dice que Iommi y Buttler sorprendieron a Dio por la noche en el estudio subiendo sus voces y esto, entre otras cosas, dió lugar a la salida del cantante que comenzó su propio proyecto Dio. A lo largo de las décadas de 1980 y 1990 pasaron cuatro vocalistas más: Ian Gillan (Deep Purple), Glenn Hughes, Ray Gillen y Tony Martín. En 1992 se produjo el regreso de Ronnie James Dio, tras un acercamiento (alentado por Buttler) con Iommi, quien más tarde se arrepintió de abandonar el proyecto anterior. Incluso se quejó del millón de dólares que costó el año de producción, repleto de problemas fruto de la tensión (sobre todo por las letras) del tercer y último disco de Dio como vocalista de Black Sabbath: Dehumanizer (1992), el cual incluye la Literary Cover que se analiza a continuación. Una vez más, a pesar de los buenos resultados, la confrontación era inevitable, y la gota que colmó el vaso fue cuando Iommi, a mitad de gira promocional, aceptó "telonear" en los dos conciertos del primer retiro de Ozzy Osbourne, a espaldas de Dio. Como era de esperar, el vocalista actuó hasta la noche anterior y se centró en su banda homónima de Heavy Metal, ya consolidada desde los 80 .

La alineación original se reunió en 1997 y publicó un álbum en directo, Reunion, cuya canción "Iron Man" ganó el premio Grammy en 2000, treinta años después de su publicación original en Paranoid. Fueron incluidos en el salón de la Fama del Rock en 2005. El grupo de comienzos de los 80, formado por Iommi, Butler, Dio y Vinny Apice (batería de Dio), se reunió en 2006 bajo el nombre de Heaven and Hell, título extraído del álbum del mismo nombre. Tras muchos años, la comunicación entre Ozzy y Iommi se reactivó cuando el segundo viajó a Los Ángeles con motivo del fallecimiento de Dio en 2010. En 2013 y después de 35 años, se anuncia la reunión de la formación original a excepción del batería. Osbourne, Iommi y Butler graban 13, el primer disco de estudio de la banda desde 1978, cuya posterior gira mundial no se realizó por problemas de salud y contractuales. 


\section{B) LETRA ORIGINAL Y TRADUCCIÓN}

\section{"Time Machine"}

Oh what are you gonna do

When there's a part of you

That needs to run with the wind

And the fire of burning yesterdays

Can only light the way

To lead you from

The garden of the dark

Stay out of shadows

Now look like the change is on

Tomorrow's never gone

Today just never comes

Go on and jump, yeah

Into the hurricane

You will forget the pain

It's only there

To exorcise your mind

Looking at the world

When you've open up your eyes

You've got to see the promises they've made

They're bloody lies and broken dreams

Your silence screams
"La Máquina del Tiempo"

¡Oh!, que vas a hacer

Cuando hay una parte de ti

Que necesita correr con el viento

Y el fuego de las hogueras del ayer puede solamente iluminar el camino que te llevará desde

el jardín de la oscuridad

(a) no volver a la casa de las sombras ${ }^{6}$.

Ahora parece que el cambio empieza

el mañana no ha llegado nunca

el presente nunca acaba de llegar.

Continúa y salta, si

Dentro del huracán

Olvidarás el dolor

solo está ahí

para exorcizar tu mente.

Mirando al cielo

Cuando has abierto tus ojos

Has tenido que ver las promesas

que han hecho

Son condenadas mentiras

y sueños rotos

Tu silencio grita.

\footnotetext{
${ }^{6}$ Nota a la traducción: teniendo en cuenta el significado de stay out como "no volver a casa", me parece más acertada esta alternativa que tan sólo "quedarse fuera de las sombras"
} 
[Chorus:]

You're living

in a time machine

And you can choose just who you are

Someone that you've never seen

Somewhere you've never been

You're ling in a time machine.

Oh what are you gonna do

When every part of you

Just needs to catch the wind

And the fire of burning yesterdays

Can only light the way

To lead you from

The garden of the dark.

Looking for the world

When you've opened up your eyes

You'll see you've got invisible chains

They're only lies

Not what it seems

I hear your silent screams.

\section{[Chorus:]}

You're living

in a time machine

Nobody cares just where you go

Taken where you've never been

go somewhere you don't know

You're living

in a time machine

Why do you stay who you are

Be what you've never been

Someone you've never seen

You're living in a time machine

Yeah
[Coro:]
Estás viviendo
en una Máquina del tiempo
Y puedes elegir quién eres

Alguien que nunca has visto

En algún sitio donde nunca has estado

Vives en una Máquina del Tiempo

Oh, qué vas a hacer

cuando cada parte de ti

solamente necesita alcanzar el viento

Y el fuego de las hogueras de ayer

pueden solamente iluminar el camino

que te llevará desde

el jardín de la oscuridad.

Buscando el mundo

cuando has abierto tus ojos

verás que tienes cadenas invisibles.

Sólo son mentiras

No lo que parece

oigo tus gritos silenciosos.

[Coro:]

Estás viviendo

en una Máquina del Tiempo

A nadie le importa a dónde vas escoge donde nunca has estado alguna parte que no conozcas.

\section{Estás viviendo}

en una Máquina del Tiempo

Porque te quedas donde estás

Sé algo que nunca has sido

Alguien que nunca has visto

Vives en una Máquina del Tiempo

$\mathrm{Si}$ 


\section{C) COMENTARIO E INTERPRETACIÓN}

Esta canción es una Literary Cover de tipo D, porque es una adaptación totalmente libre del concepto expuesto en la obra de Wells, ya que ni siquiera trata de un viaje en el tiempo; sólo se usa el concepto para referirse por asociación a la posibilidad de estar en cualquier parte o ser cualquier persona. Por tanto no podemos hablar de una versión de la historia, adaptación, ni siquiera de una continuación o secuela, ya que el término ha sido apropiado y deformado a conveniencia, usándolo tan sólo para referirse a una situación hipotética, que en cierto sentido tiene alguna similitud con el concepto original ideado por Wells. Este hecho es muy común en el Rock'n'Roll; en ocasiones se considera más importante cómo suena la letra que lo que en realidad dice, como en el caso de esta canción en la que la máquina del tiempo se refiere a la posibilidad que tiene una persona de cambiar su vida. En cierto modo, el viaje en el tiempo, más que una investigación científica o una búsqueda, es una metáfora que responde al ansia de libertad expresado en la primera estrofa «Oh what are you gonna do / When there's a part of you / That needs to run with the wind. »

Solamente realizando un análisis exhaustivo de la canción podemos interpretar el texto musical de manera que aparezca alguna relación con la novela. Por un lado, hay algunas imágenes simbólicas que se pueden asociar al mundo de los Eloi y los Morlocks, más concretamente a éstos últimos «the garden of the dark»y, sobre todo, esa casa de las sombras de la advertencia «Stay out of shadows». Desde esta perspectiva de lectura, las «invisible chains», en vez de referirse a la asfixiante realidad, se pueden entender como el control mental con el que los Morlocks apresan al viajero del tiempo, tal y como sugiere el título y la portada del álbum con ese concepto del "deshumanizador". Encontramos, además, otros indicios en los que se puede establecer relación con el viaje en el tiempo, como en la estrofa «Looking at the world / When you've open up your eyes /You've got to see the promises they've made / They're bloody lies and broken dreams / Your silence screams.» en la que podemos interpretar que la realidad temporal a la que el viajero llega le impacta hondamente. Otra visión del viaje temporal se expresa en el verso «Go on and jump / into the hurricane», que lo define como una especie de salto a un vórtice temporal. Por último, en la cuarta estrofa se puede interpretar la sensación del viaje temporal: «Now look like the change is on / Tomorrow's never gone / Today just never comes. »

Por otro lado, la canción forma parte de la banda sonora de la película Wayne's World (1992), una parodia del mundo del Rock. Por último, en el aspecto musical, huelga decir que este tema es clásico del género y de la banda, muy representativo del período de Black Sabbath con Ronnie James Dio a la voz, que después se conocería como The Dio Years (como reza el título del disco recopilatorio) y que, más tarde, se conocería con el nombre de Heaven and Hell. Un período bien diferente al primero de la banda con Ozzy, pero que, de la misma manera, ha creado escuela con una cuidada elaboración y una gran creatividad. 


\section{PROPUESTA DIDÁCTICA PARA SU DESARROLLO EN EL AULA}

\subsection{Introducción: planteamiento y objetivos}

En las aulas de inglés, tanto de Enseñanza Secundaria como en cursos de Filología inglesa (preferiblemente, cuando el alumnado esté estudiando la Literatura Fantástica Victoriana), escuchar, comprender, interpretar, cantar, traducir y/o reelaborar creativamente las canciones analizadas en este artículo son acciones motivadoras que pueden producir beneficiosos efectos de aprendizaje en sus destinatarios.

Dichas acciones requieren que el alumnado actualice y desarrolle tanto las cuatro macrohabilidades generales y propias de la competencia lingüística (escucha, expresión oral, comprensión lectora y expresión escrita), como la competencia literaria crítica.

La realización de dichas acciones servirá, posteriormente, de motivación e introducción a la lectura comprensiva y crítica de ciertas novelas o fragmentos emblemáticos de Literatura Fantástica Victoriana, cuyos ecos perduran en dichas canciones.

Además de los objetivos planteados en los párrafos precedentes, buscamos que el alumno entienda las relaciones intertextuales y transtextuales destacadas por el profesor, así como que sea capaz de extraer sus propias conclusiones y de indagar, entre sus gustos literarios y musicales a la búsqueda de cualquier tipo de conexión, o que extienda este enfoque al cine, TV, pintura, comic, etc. El verdadero propósito de esta propuesta didáctica es, en efecto, incitar al alumnado a que supere el planteamiento convencional de los estudios literarios e incluso del de los culturales populares y desde la perspectiva de la literatura comparada explore otras obras, otros autores, otras corrientes en relación con cualquier manifestación artística.

\subsection{Desarrollo: metodología práctica}

Para concretar la dinámica del proceso de enseñanza-aprendizaje, los contenidos que pueden exponerse en el aula son los que corresponden a los siguientes epígrafes desarrollados en el artículo:

1. Literatura Comparada. Estudios Culturales Populares. Literary Covers y su categorización.

2. Narrativa Fantástica de H. G. Wells. The Invisible Man. The Time Machine.

3. Estudio y análisis de las Literary Covers. Queen. Black Sabbath.

En las sesiones de trabajo, cada alumno dispondrá, en fotocopia, de las letras de las dos canciones, así como el aula de los medios audiovisuales requeridos para la reproducción multimedia.

Metodológicamente, tras recabar y actualizar los conocimientos previos del alumnado, el profesor ofrecerá la información necesaria para contextualizar la propuesta; por su parte, la audición y el visionado de las canciones y videos contará con una breve presentación y sugerencias para que el alumnado pueda 
captar la comunicación dialógica directa, mediante la primera persona, en el primer ejemplo y en $2^{\mathrm{a}}$ persona en el segundo, que se expresa en ellas, así como el léxico e imágenes recurrentes con que lo hacen. Posteriormente desde dichas imágenes, reconocidas por el alumnado, se podrán establecer los puentes de conexión con las imágenes y motivos presentes en los fragmentos de las novelas fantásticas victorianas que les dieron origen y podrán trabajar dichos textos narrativos del mismo modo que las canciones. Las audiciones y visionados pueden organizarse y temporalizarse del siguiente modo:

1.- Escucha del tema de Queen (4 minutos)

2.- Visionado del videoclip de Queen (4 minutos)

3.- Escucha del tema de Black Sabbath (4 minutos)

4.- Segunda escucha (o visionado) del tema de Black Sabbath (4 minutos)

Como no hay videoclip del tema de Black Sabbath, para la segunda audición de éste, sería recomendable poner la versión en directo de su último concierto, recogido en el video Live in Oakland 1992, fácilmente accesible en Youtube.

Tras la audición de cada canción, y después de algunos minutos de reflexión en silencio, el alumnado, distribuido en pequeños grupos de 3 a 5 personas, realizará un análisis pormenorizado del mensaje comprendido, de la tipología textual de la letra; del modo de comunicación y características del personaje, con sus rasgos de personalidad y poderes verdaderamente "singulares"; de las expresiones reiteradas y las palabras clave, etc.; estas anotaciones les servirán de base para la escritura de un breve texto expositivo en el que sintetizarán lo comprendido y aprendido. También podrán realizar, individualmente, tomando la canción como modelo, una autodescripción, real o ficticia, en la que plasmarán la dimensión creativa de la escritura y para cuya realización habrán de movilizar conscientemente los recursos lingüísticos y literarios de que dispongan.

Desde una dimensión académica más rigurosa, podemos, además, proponer que el alumnado traduzca fragmentos emblemáticos de las obras consideradas así como las letras de las canciones seleccionadas y escriba un ensayo crítico sobre el tema, bien en lengua materna o en lengua inglesa, si se trata de alumnos aventajados, alumnos bilingües o aficionados al Rock con un buen nivel de uso de la lengua inglesa.

La propuesta didáctica hasta aquí esbozada, podría contar con tres o cuatro sesiones de clase; su planteamiento implica una nueva concepción de la literatura y su influencia en todos los ámbitos de la cultura moderna, y aspira a que, tras su puesta en práctica, el alumnado adopte y muestre nuevas inquietudes y competencias al respecto. 


\section{CONCLUSIONES}

El contenido de este artículo permite, por un lado, poner de manifiesto la influencia de la Literatura en el Rock'n'Roll mediante el estudio y análisis de su máxima expresión que son las Literary Covers, y, por otro lado, destacar la posibilidad de aplicación pedagógica que el análisis de estas canciones ofrece para facilitar el acercamiento del alumnado a los clásicos de la literatura en los que se han inspirado los autores de dichas canciones. De hecho, como he esbozado en el epígrafe anterior, las aportaciones de este artículo son susceptibles de verterse en una unidad didáctica dirigida a jóvenes adultos universitarios (e incluso adolescentes de Bachillerato) destinada al aprendizaje y fomento de la lectura de los autores clásicos literarios. Así mismo, resulta de gran utilidad para que cualquier aficionado al Rock pueda explorar las fuentes literarias de los artistas que, como los canciones analizadas, crearon composiciones musicales basadas en obras literarias. Bajo este enfoque, se puede considerar que propuestas de este tipo pueden contribuir al desarrollo de la competencia literaria del alumnado que, partiendo del Rock alcanza el conocimiento y gusto por los textos literarios, en este caso, por las obras H. G. Wells. Efectivamente, esta propuesta revitaliza el interés del oyente por la lectura o relectura de la obra de dicho autor. Por tanto, el principal objetivo de este trabajo, y de mi investigación en general, es abrir una vía en los estudios culturales populares, analizando, entre otras, las conexiones literarias en el Rock'n'Roll, manifiestas y latentes en las versiones literarias o Literary Covers.

Desde un punto de vista teórico-práctico, la categorización de las Literary Covers responde a la necesidad de catalogar esta influencia o puente de comunicación entre ambas corrientes. En este artículo, se constata, mediante el análisis de las dos canciones consideradas, que la mayoría de estos vínculos suelen ser de tipo $\mathrm{C}$ y $\mathrm{D}$, ya que las versiones musicales, no sólo de la Literatura Fantástica sino de cualquier corriente literaria, suelen ser adaptaciones contemporáneas (como en el caso de Queen) o versiones libres (como en el caso de Black Sabbath).

Después de valorar la conexión entre ambas manifestaciones culturales, no se puede negar que tanto el autor literario como los artistas musicales son exponentes de un movimiento innovador, con una fuerza creativa tan grande que han seguido manteniendo esa chispa primigenia que los ha convertido en universales y atemporales, a pesar de haber sido primero rechazados y posteriormente asimilados social y culturalmente.

Más allá de un relato extraordinario y rompedor, o una canción que recupera este trabajo, las obras que se comentan aquí tratan de demostrar que tanto la Narrativa Fantástica de H. G. Wells, como el Rock no son modas pasajeras, sino que forman parte del imaginario cultural popular occidental, en los últimos siglos, desde finales del XIX al principios del XXI. 


\section{BIBLIOGRAFÍA Y DISCOGRAFÍA}

\subsection{Bibliografía}

ANDERSON, Linda R. Bennet, Wells and Conrad: narrative in transition.

Macmillan editions. Basingstoke Macmillan, $1^{\text {st }}$ edition, (1988)

ASHLEY, Robert. The Study of Popular Fiction: A source Book. Continuum International Publishing (1989).

ASTURIAS, Miguel. Black Sabbath, cuatro décadas entre el cielo y el infierno. Biografía no autorizada. Quarentena Ediciones, Barcelona (2008)

BARKER, Chris. Cultural Studies: Theory and Practice. SAGE Publications Ltd. $4^{\text {th }}$ ed. (2011).

CAMARERO, Jesús. Intertextualidad: redes de textos y literaturas transversales en dinámica intercultural. Colección Pensamiento crítico / Pensamiento utópico. $1^{\mathrm{a}}$ ed. Editorial Antrophos, Barcelona. (2008).

DRAPER, Michael. H. G. Wells. Ed. Macmillan modern novelist. (1987).

GUILLÉN, Claudio. Entre lo uno y lo diverso: Introducción a la literatura comparada. Colección Filología. Editorial Crítica. Barcelona (1985).

JONES, Lesley-Ann. Freddie Mercury: La biografía definitiva. Trad. Alejandro Pradera. Libros singulares LS, Edición Alianza (2012).

LLOVET, Jordi. Teoría literaria y literatura comparada. Colección Literatura y Crítica. $1^{\mathrm{a}}$ ed. Ariel. Barcelona, (2005).

O'HAGAN, Sean. Freddie Mercury: The Great Pretender. A life in Pictures. Carlton Books. (Freddie Mercury: Una vida en imágenes). Edición Oficial. Libros Cúpula (2012)

MENDOZA FILLOLA, Antonio. Literatura comparada e intertextualidad: una propuesta para la innovación curricular de la literatura (Educación Secundaria). Colección Aula Abierta. Editorial La Muralla. Madrid (1994).

MERCURY, Freddie. Freddie Mercury: su vida contada por él mismo(A life in his own words). Compilado por Greg Brooks y Simon Lupton. Musica Ma Non Troppo (2012).

PICHOIS, Claude y ROUSSEAU, André. La literatura comparada. Trad. Germán Colón. Colección Románica Hispánica Manuales. Ed. Gredos, Madrid, (1969)

RODRIGUEZ, Julián. Antología de literatura universal comparada: Materiales para la enseñanza práctica de la literatura a través de la experiencia literaria, visual y musical. Universidad de Murcia. (1991).

RODRÍGUEZ, Julián (2). Curso básico de literatura comparada. Ed. Editorial Ega, Bilbao (1992), $1^{\text {a }}$ ed. Colección Didaktiké.

SCOLARI, Carlos Alberto. No pasarán: las invasiones alienígenas desde H.G. Wells hasta S. Spielberg. Editorial Páginas de Espuma, $1^{\text {a }}$ edición, Madrid (2005)

SUTCLIFFE, Phil. Queen: La Historia Ilustrada de los Reyes del Rock (The Ultimate Ilustrated History of the Crown Kings of Rock). Trad. Santiago Nudelman. Editorial Grijalbo, $1^{\text {a }}$ edición. (2010) 
STOREY, John. Cultural Studies and the Study of Popular Culture. University of Georgia Press, $2^{\text {nd }}$ ed. (2003).

VEGA, Maria Jesús y CARBONELL, Neus. La literatura comparada: principios y métodos. Colección Manuales. Editorial Gredos, Madrid, (1998).

VV.AA. 40 años de Queen. Traducción María José Espinoza Saavedra. Prólogo de Brian May y Roger Taylor. Libros Cúpula. (2011).

VV.AA. Cultural Studies: An Anthology. Michael Ryan (ed). Willey - Blackwell, $1^{\text {st }}$ ed. (2008).

VV.AA. The Aesthetics of Cultural Studies: An introduction. Michael Berube (ed). Blackwell Publishers (2004).

VV.AA. The Renewal of Cultural Studies. Paul Smith (ed). Temple University Press (2011).

VV.AA. The Rolling Stone Enciclopedia of Rock\&Roll (Revised and updated for the $21^{\text {st }}$ Century). Edited by Holly George-Warren, Patricia Romanowski and Jon Pareless. Fireside, New York, (2001).

WELlS H. G., (1897) The Time Machine and The Invisible Man. Digireads.com (2009).

WELLS H.G. (2). (1896) El Hombre Invisible. Trad.: Julio Gómez de la Serna. $5^{\text {a }}$ ed. Anaya (2011).

WELLS H.G. (3). (1895) La Máquina del Tiempo. Trad.: Nellie Manso de Zúñiga. EL PAIS (2004).

WELLS H.G. (4). Autobiografía. Descubrimientos y conclusiones de un cerebro muy normal. Editorial Berenice S.L. $1^{\text {a }}$ Edición. Córdoba (2009)

WEST, Anthony (1914). H.G.Wells. Aspectos de una vida. Trad.: Miguel Martínez Lage. Editorial Circe Barcelona. (1993)

WICKE, Peter. Rock Music: Culture, Aesthetics and Sociology. Cambridge University Press (1990).

\subsection{Discografía}

BLACK SABBATH. Dehumanizer (1992). Reprise Records.

QUEEN. The Miracle (1989) Parlophone (EMI). 